\title{
The 49th General Meeting of the German Colloid Society, 23-25 September 2019, Stuttgart, Germany
}

\author{
Thomas Sottmann ${ }^{1}$
}

Received: 2 December 2020 / Accepted: 7 December 2020 / Published online: 3 February 2021

(C) The Author(s) 2021

The 49th General Meeting of the German Colloid Society (founded 1922 in Leipzig) with the focus on "Complex Fluids" was held in Stuttgart, the capital of the German federal state of "Baden-Württemberg." Stuttgart is located in southwest Germany; the city extends over a hilly landscape, which is marked by vineyards, valleys, and parks. The meeting that took place from September 23 to 25, 2019, was organized by the soft matter groups of the Institute of Physical Chemistry of the University of Stuttgart (Fig. 1), which is one of the leading technically oriented universities in Germany.

The meeting chaired by Cosima Stubenrauch and cochaired by Frank Gießelmann, Peer Fischer, and me focused on the following research topics selected from the wide field of complex fluids:

- Active colloids

- Colloid dynamics and manipulation

- Self-assembly

- Surfactant self-assembly

- Microgels

- Liquid crystals

- Materials

- Methods

- Applications

The event was attended by more than 140 participants, including representatives of 4 exhibiting companies. A total of 54 lectures, including 5 awards and 7 invited lectures, and 31 posters (Fig. 2, left) were presented within the scope of the 9 abovementioned research topics. The meeting was sponsored by Anton Paar GmbH (Graz, Austria), Bruker GmbH (Karlsruhe, Germany), DataPhysics Instruments GmbH

Thomas Sottmann

thomas.sottmann@ipc.uni-stuttgart.de

1 Institute of Physical Chemistry, University of Stuttgart, Stuttgart, Germany
(Filderstadt, Germany), Springer Publishing Company (Heidelberg, Germany), and the Fritz Henkel Stiftung (Düsseldorf, Germany).

As for highlights of the 49th General Meeting, the following prizes were awarded by the German Colloid Society before the respective award lecture. After the welcome address of Cosima Stubenrauch, Dominique Langevin (Paris, France) received the Ostwald Prize honoring her outstanding scientific research in the area of fundamental colloid science (Fig. 2, right). In the evening session, Werner Kunz (Regensburg, Germany) was awarded with the Steinkopff Prize for outstanding achievements in the field of industrial and technological applications of colloid science. During the second day, Tobias Kraus (Saarbrücken, Germany) received the Liesegang Prize, which is reserved for scientists in the midst of their career, for outstanding achievements in the area of colloid science. The last day started with the rewarding of the Graham Prize to Michal Borkovec (Geneva, Switzerland) for his outstanding accomplishments in the field of colloid science in an international context. Last but not least, André Gröschel (Münster, Germany) received the Zsigmondy Scholarship for excellent young scientists working in the area of colloid science.

Sponsored by the Springer Publishing Company and the Colloid Society, five young scientists were awarded for their poster presentation. Springer also sponsored the Springer Lecture given by Véronique Schmidt (Bordeaux, France) on the "Elaboration of double emulsion-based polymeric capsules for fragrance retention." The diversity of this international meeting is reflected in the invited lectures, which were excellently presented by Clemens Bechinger (Konstanz, Germany), Anniina Salonen (Paris, France), Orlin Velev (Raleigh, USA), Daniela Kraft (Leiden, Netherlands), Jan Lagerwall (Luxemburg), and Bernhard Binks (Hull, United Kingdom).

This special issue of the 49th General Meeting of the German Colloid Society contains 12 manuscripts based on the contributions presented at the meeting. All submitted papers underwent the full refereeing procedure of the journal. 

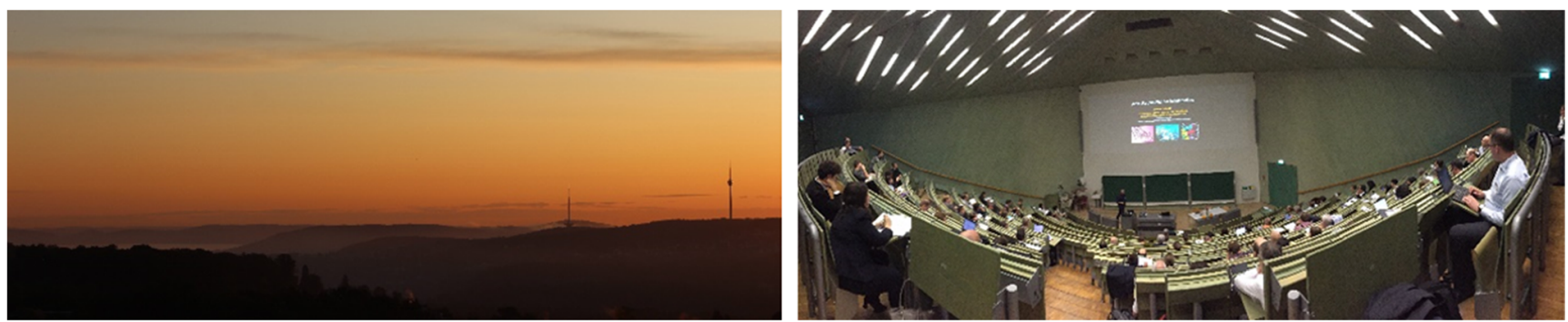

Fig. 1 Left: Photo taken from the meeting venue at the campus "Vaihingen," located $10 \mathrm{~km}$ south of the center of Stuttgart. Right: Photo of the lecture hall in the computer science, electrical engineering, and information technology centre
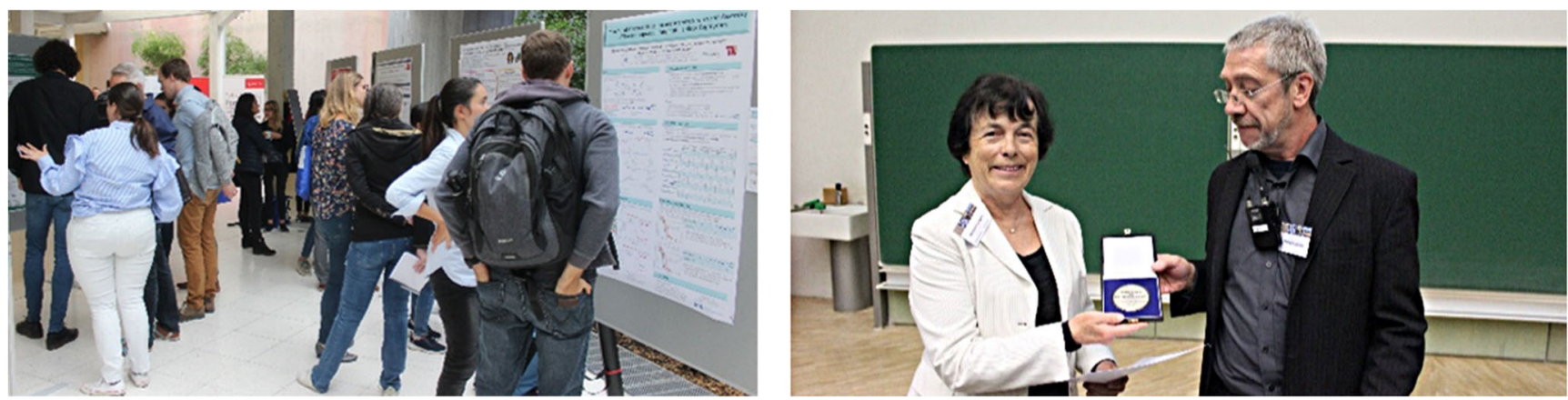

Fig. 2 Left: Photo taken during one of the two poster sessions. Right: Dominique Langevin (Paris, France) received the Ostwald Prize from Michael Gradzielski (Berlin, Germany), chairman of the German Colloid Society

The special issue starts with a perspective article of the Graham Prize winner Michal Borkovec on the SchulzeHardy rule followed by the invited Springer Lecture article of Véronique Schmidt on double emulsion-based polymeric capsules. This special issue takes you on a journey through colloid chemistry ranging from the synthesis, properties and applications of thermo-responsive polymers, the formation of macroporous polymers, mesoporous foams and $\mathrm{ZnO}$ inverse opals, the development and application of new techniques such as super-heterodyne dynamic light scattering (DLS), and in situ Magnetorheo small-angle neutron scattering (SANS) at the Institute Laue Langevin (Grenoble, France), as well as diffusive dynamics of particles and in different active colloidal suspensions.

Finally, we would like to thank everyone who contributed to ensuring the success of the 49th General Meeting of the German Colloid Society.
Funding Open Access funding enabled and organized by Projekt DEAL.

Open Access This article is licensed under a Creative Commons Attribution 4.0 International License, which permits use, sharing, adaptation, distribution and reproduction in any medium or format, as long as you give appropriate credit to the original author(s) and the source, provide a link to the Creative Commons licence, and indicate if changes were made. The images or other third party material in this article are included in the article's Creative Commons licence, unless indicated otherwise in a credit line to the material. If material is not included in the article's Creative Commons licence and your intended use is not permitted by statutory regulation or exceeds the permitted use, you will need to obtain permission directly from the copyright holder. To view a copy of this licence, visit http://creativecommons.org/licenses/by/4.0/.

Publisher's note Springer Nature remains neutral with regard to jurisdictional claims in published maps and institutional affiliations. 